\title{
CLIMATE ADAPTABILITY OF OLD AND NEW HOUSE IN BUSHEHR'S HISTORICAL TEXTURE
}

\author{
Nadiya MOZAFARI ${ }^{1, *}$, Masoud ALIMARDANI $^{1}$ \\ ${ }^{1}$ Faculty of Architecture and Urbanism, Shahid Rajaee Teacher Training University, Tehran, Iran. \\ corresponding author: nadiya.mozafari@gmail.com.
}

\begin{abstract}
The port of Bushehr, with its valuable and unique historical texture, completely matches with its unbearable climate conditions. Over hundreds of years, the port has provided an appropriate ground for human life as no air conditioner is needed there. Unfortunately, this valuable old texture has been destroyed inadvertently. New buildings in the port are just superficial copies of the old buildings' external surfaces, with no attention to their goal, i.e., the provision of thermal comfort for inhabitants. The new buildings are dramatically increasing without considering the historical texture and climate. As a result, the inhabitants have to use air conditioners in most months continuously; hence, there would be an increase in energy consumption and a disruption in climate balance. This study has been conducted to compare the compatibility of such architecture with the climate and its success in providing climate comfort for the inhabitants. According to the information obtained from the study, the old houses built more than 100 years ago using traditional design had better performance in adaptability with climate. Accordingly, the exploitation of traditional instructions and patterns in a new format would largely reduce energy consumption in hot seasons and eliminate the need for heating in cold seasons. In this regard, a huge amount of energy is saved, resulting in less damage to the environment.
\end{abstract}

\section{Keywords:}

Bushehr's historical texture; Wind flow;

Climate;

Thermal comfort.

\section{Introduction}

Designing urban spaces and buildings is of paramount importance in controlling and using wind flow in hot and humid weather. Wind flow is usually influenced by the layout of masses and spaces and their situation, density and height. With designing urban spaces and buildings in accordance with the climate, it is possible to control the wind flow and use it to improve the weather. This is of great importance, especially in cities built in hot and humid climates. Unfortunately, despite the irrefutable role of wind in forming Bushehr's old architectural texture and the possibility of using its valuable experiences in designing new buildings, no accurate scientific study has examined their use in new architectural designs. The common types of new buildings, which are remarkably increasing, are not built with regard to the texture and climate. By recognizing the wind function and finding simple techniques to exploit it in the historical texture of Bushehr, instructions can be supplied for new buildings to match the climate and texture and prevent the energy loss and environmental degradation. This study attends to find the answers for these following questions: which methods were common in the old texture of Bushehr that had made the unbearable climate conditions better over hundreds of years. Do the new types of common architecture are as comfortable as the old ones to provide climate comfort. And how we can compare two kinds of those buildings in the amount of successfulness to provide climate comfort for inhabitants. At last how we can improve our new architecture according to the climate and the historical context. To find the answers in the first step we have to study about historical texture in Bushehr with its special vernacular architecture in three scales: urban texture, architecture units and details. 


\section{Theoretical foundations}

\subsection{The port of Bushehr}

Bushehr province is located in the south of Iran on the north coast of the Persian Gulf, Fig. 1. The foundation of Bushehr province dates back to the Elamite era, according to the historical remains found in Rishehr city, which is adjacent to Bushehr. Bushehr port was built in the Afsharian era (1736 1796) when king Nader built a fort on the port and made it a naval station. Bushehr province has two main seasons: short winter that is relatively cool just in December, January, and February and extremely hot and long summer. The average annual temperature is reported to be about $24^{\circ} \mathrm{C}$, with the hottest and coldest recorded temperatures being about $50{ }^{\circ} \mathrm{C}$ and $6^{\circ} \mathrm{C}$, respectively. The north wind is the most famous local wind in Bushehr, which blows from northwest and is the only wind that can make the hot summer cooler; hence, many old windows in Bushehr were placed in the direction of this local wind [1]. In this region, making shadows and using wind flow are the best choices to cope with harsh weather conditions [1].

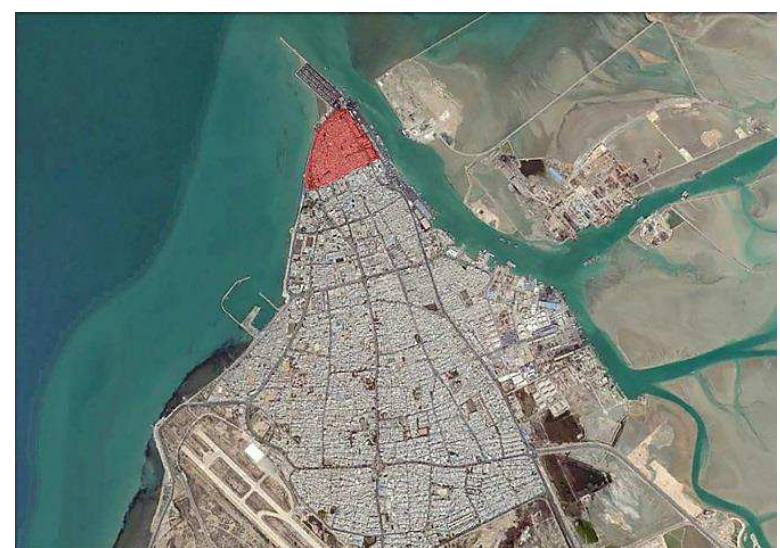

Fig.1: Old context of Bushehr [Google Earth].

\subsection{Traditional urban spaces with regard to the climate}

Peninsula composition of Bushehr port has provided an appropriate condition to catch wind from different directions. In order to reduce the excruciating heat from the sunlight, most building blocks are placed in the east-west direction, Fig. 2. In addition to the possibility of using multiple benefits of the wind flow, the buildings of the old texture are placed in different directions. The angle between buildings and wind flow was about 90 degrees, which allowed buildings to have better air ventilation [2]. Buildings are built in both tiny single house patterns and large block building patterns, with the latter usually including several small houses with several intersecting alleys around them in order to better exploit the wind flow [3].

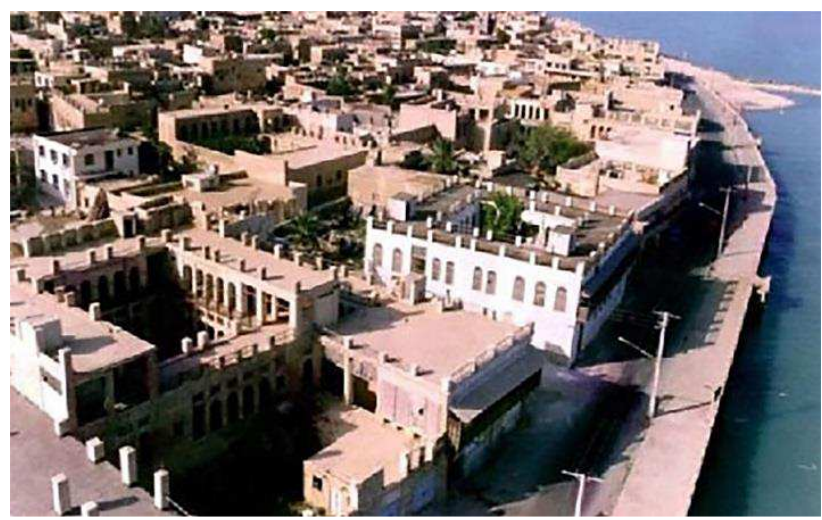

Fig. 2: Bushehr's old texture [4].

The main streets are built in the sea direction. The ratio of the width of alleys to the height of buildings was usually $1-10$. In this regard, the covered alleys were observed in several neighborhoods; hence, permanent shadowing on the alleys was mostly observed [5,6]. The large 
number of junctions between alleys and open spaces improves the wind flow direction and moves it to different parts of the old texture. The width of the alley was reduced from lower to higher levels so that it could increase wind flow near the ground. In addition to bringing thermal comfort for passer-byes, the wind flow absorbs the moisture from the external walls, which are mainly made of porous coral rocks and make the indoor places cooler [7].
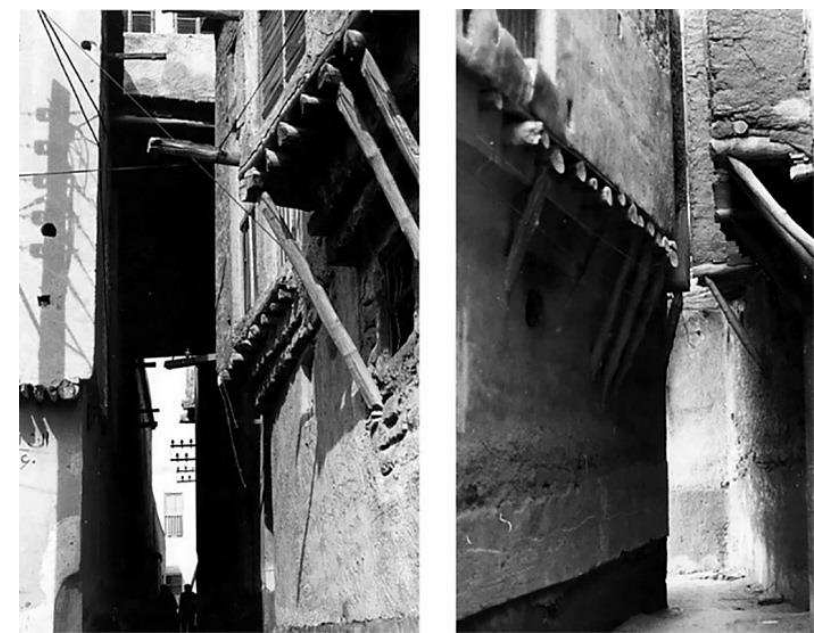

Fig. 3: Narrow alleys in Bushehr's old texture [4].

One of the main parts of urban spaces in Bushehr's old texture were plazas, which not only had social functions but also caused wind distribution, Fig. 3. The form of these plazas was affected by the wind flow so that more wind was received. The buildings had many openings on their surfaces. Creating height difference was an important method to use regional wind dental texture at the junction of the building and the sky and the special location of high buildings among the lower buildings, at the edge of open spaces, have made more wind distribution and conducted it to lower levels [7].

\subsection{Effects of climate on Bushehr architecture}

One of the main parts of Bushehr's old houses were courtyards, Fig. 4. They were usually surrounded by high buildings and were less occupied in comparison to the other parts of the house, so they had been encircled in most months of the year and were in shade and cool [5, 8]. In addition to organizing different places around them, they played a key role as a natural ventilator. A large number of openings were placed on the external and internal elevations, thereby providing an appropriate condition for increasing wind flow speed and directing it toward the desired residential spaces. The wind flow grabbed from out of the house passed through different places and exits from the courtyard [8].

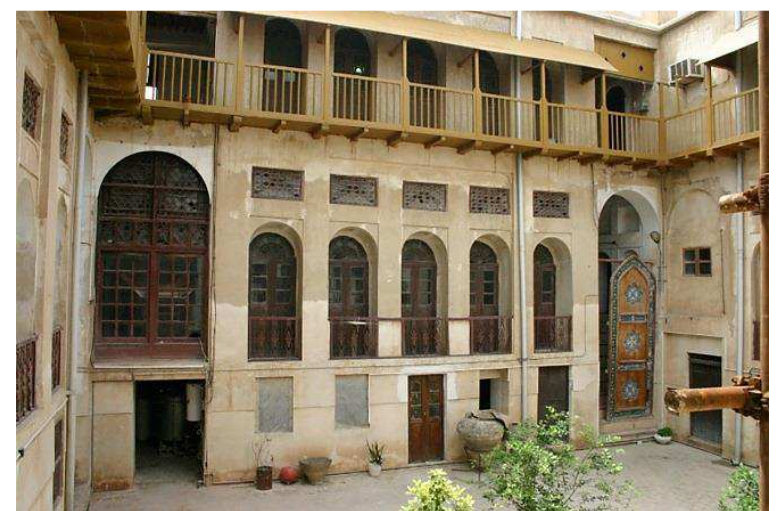

Fig. 4: Courtyard in Bushehr's old house [4].

The wind flow is exposed to the roof and courtyard, which enhanced ventilation via openings [2]. Roofs had a function as a wind outlet were placed in negative airway pressure or suction part of the building. The suction part was created by flowing the wind on the building and helped the ventilation 
[8]. In higher heights of dense urban texture, the sea breeze can be used better. So in order to have a better function, wood railing parapets were built at roofs allowing the wind flow to cross inside [5]. Inhabitants sometimes used to set up pergolas on the roof and sleep in them in hot seasons [5, 9]. Bushehr's old houses had no basement due to the high level of groundwater; hence, the buildings were constructed directly on the ground or a little higher [5]. Servicing places such as kitchen, storage, and bathroom were placed on the ground due to the great amount of moisture and heat. The special rooms for cold seasons, which had a few and small openings and were warmer in winters, were placed on the ground [2, 9]. In the upper levels (about 4 to 5 meters), special rooms for hot seasons were placed due to receiving more wind flow and preparing better thermal comfort in order to provide better ventilation. Generally, in higher places, hot air moves toward upper sections of the room, and cold air moves toward lower sections; therefore, wind flow is facilitated through many openings [5]. A vertical connection between openings at different levels also provided better ventilation [2]. Bilateral openings on both external elevations to the alley and internal elevations to the courtyard made twoway wind flow in the rooms [2,5]. Three common types of rooms (namely living room, dining room, and bedroom) have been found, which were named on their door numbers and usually had three, five, or seven doors. The rooms had different functions at different times [10].

Tarmeh is a type of porch in old houses of Bushehr, which was common in Iranian architecture. It was a semi-open space, i.e., open on one side and sometimes with no roof. It was used as a seasonal, temporary living room or a good connecting space for bedrooms, which were usually beside the stairs [9]. By making a vertical connection between different levels, the stairs were used as a vertical ventilator [2].

Shenashil is a kind of wood louver balcony that was common in old houses of Bushehr (Fig. 5), usually used in the exterior elevations, to provide shading on the wall and openings and conduct the wind flow into the building [2]. Furthermore, this way inhabitants were not watched from outside [9]. In some cases, shenashil was built in upper levels of interior parts of the building, in order to make shades on the courtyard and connect the rooms from outside.

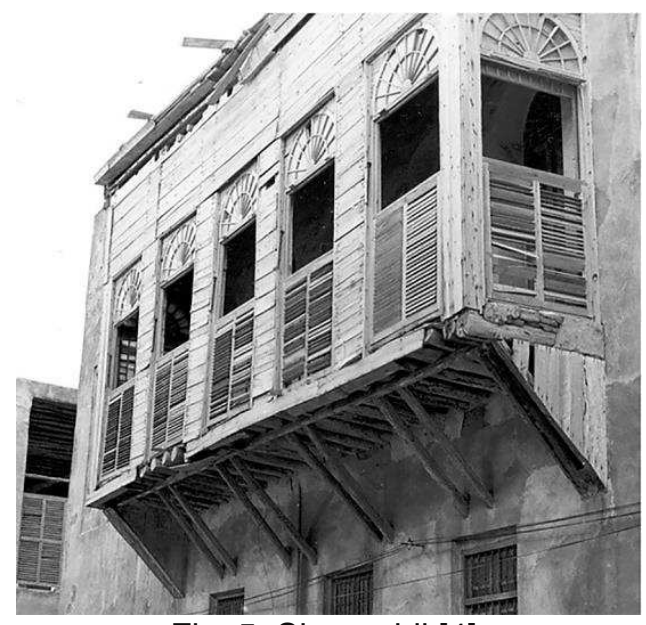

Fig. 5: Shenashil [4].

Openings played an important role in directing wind and contributed to natural ventilation in the buildings. Placing many openings in the wind direction causes faster wind flow in the rooms. Moreover, placing them in sidelong walls facilitates wind circulation [2]. The amount of wind flow depends on the number of openings and their dimensions. Many techniques were used to reduce the persecutor effects of the direct hot radiation on the openings and walls, one of which was the use of wood louvers. The openings were mainly made of wood; however, a small part of them was made of colorful glass which reduced the hot radiation. The openings were usually placed in the depth of the thick wall, in which design louvers were employed. This decreased the annoying hot sunlight radiation on doors and windows by extending shadows on the openings [11]. The valves of the double doors could be open or closed together or separately to control the direction and amount of incoming wind, and the output wind could enhance the natural ventilation, Fig. 6. For example, when they were open to the outside, there was a high-pressure area beside one door and a low-pressure area beside another one to facilitate wind circulation [8]. 


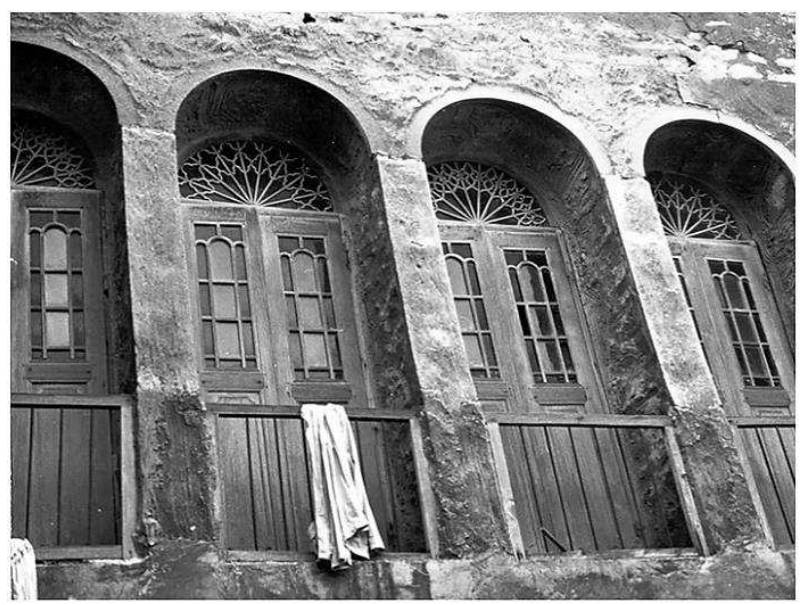

Fig. 6: Traditional double doors in Bushehr's old houses [4].

Using special materials with a low amount of thermal mass that do not keep the heat in them is a practical solution for buildings in hot and humid climates. Wood is one of the best materials because it transfers the heat slowly and also loses the absorbed heat of daily sunlight at night. Due to the shortage of wood and trees in Bushehr province, this material is not used so much in buildings [5]. The walls were made of high thermal mass materials with a high thickness (the thickness was sometimes almost one meter) to tolerate the heavy weight of upper levels [5]. The high thickness also reduced the heat transfer into the building. One of the more common stones in these buildings was one type of coral sedimentary rock. They were soundproofed and heatproofed well because of their porosity [5].

\section{Study method}

This study was a descriptive-analytical study with practical purposes. Theoretical foundations were collected by reviewing library documents and field studies. An effort was made to compare the architectural adaptability with the climate in old and new houses and their success in providing climate comfort for the inhabitants. In this case study, both kinds of houses, an old house which is more than 100 years old and a new house which is about four years old, in one neighborhood were compared. Bushehr's climate information such as weather, temperature, wind speed, humidity, and radiation was also obtained from Meteonorm software and analyzed using ArchiCad software. Common residential places such as living rooms, bed rooms, and kitchen, where the thermal comfort is more important to the inhabitants, were studied. No mechanical and electrical cooling machines were included in order to compare the effects of building architecture on improving indoor climatic conditions and providing thermal comfort for inhabitants.

In the models simulated in this study, the location of the project and physical factors were effective in obtaining the analysis results. Factors such as architecture type, model geometry and orientation of the building, number, area, and volume of zones used by residents for permanent residence and use, uncovered areas in the building, type and thickness of walls and the materials used in them, type, area, and orientation of openings, area of glass and opaque sections in the openings, properties of the used glass (such as the amount of solar energy transmission or u-value), the perimeter of the frames of openings and the amount of air permeability where they are connected to the wall, and placement of canopies in front of openings were all influential in obtaining these results.

In the simulated models, the openings were considered open in hot seasons and closed in cold seasons. In the old sample, due to the emphasis of the architecture type on the use of vertical ventilation, the stairway has no door, and the vertical airflow from the ground floor to the roof exists in all seasons of the year. However, in the new building, the door of the loft's stairway is always locked, but the entrance door of the stairway on the ground floor is always open. These conditions were also considered in the analysis.

Morteza Kasmaei has determined the limits of the comfort zone for Iran, which is located between the latitude of 25 to 40 degrees, by creating some changes in the Olgyay bioclimatic chart (about the relationship between temperature, humidity, air current, and their impact on comfort zone). In this order, the minimum of the summer comfort zone in the aforesaid chart should be increased by three-fourth of a Fahrenheit degree for each 5-degree reduction of latitude from northern 40 degrees. 
The maximum limit of the comfort zone should also be increased by the same amount. However, it should not be more than 85 degrees Fahrenheit [12]. So the comfort range in Iran, which is placed between 25 and 40 degrees north of latitude, is considered between $21.5^{\circ} \mathrm{C}$ and $29^{\circ} \mathrm{C}$ in summers and between $20^{\circ} \mathrm{C}$ and $25.7^{\circ} \mathrm{C}$ in winters. Relative air humidity is also considered between $30 \%$ and $65 \%$. This thermal comfort condition is relative and approximate and it is supposed for someone who is sitting or working with normal clothes on [12].

\section{Analysis of the results}

The mean temperatures of different places in these two samples are presented for different months of the year according to the information obtained from the Archicad software, Table 1.

\subsection{Analyzing old house}

A 100-year-old house, located at Behbahani neighborhood, which is built, based on a type of typical architecture in Bushehr, was studied, Figs. 7 and 8.

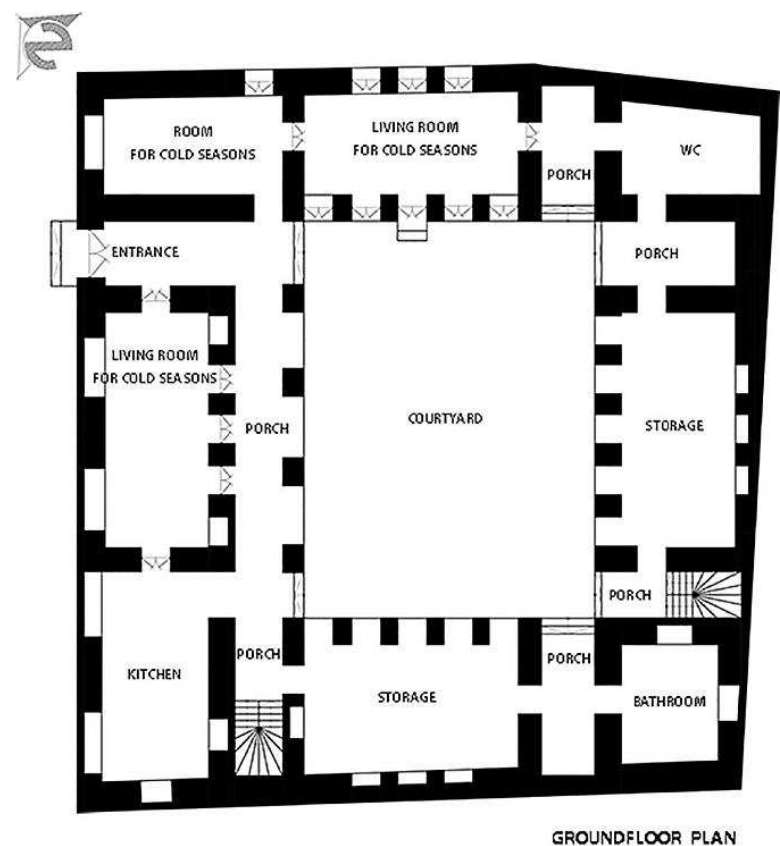

Fig. 7: Ground floor of the old house.

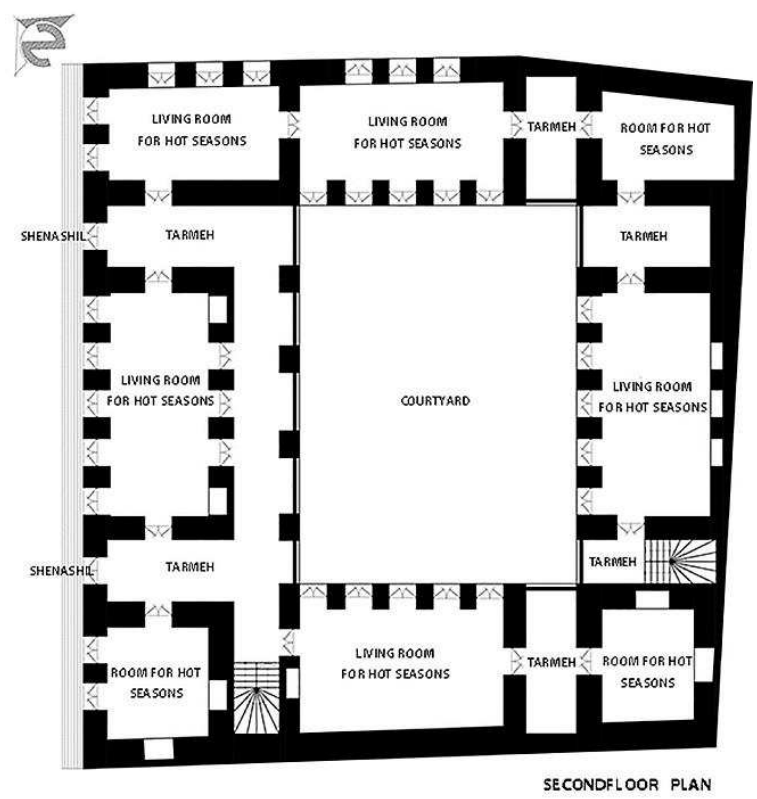

Fig. 8: Second floor plan. 
Table 1: Average monthly temperature in the old house [ArchiCard software].

\begin{tabular}{|c|c|c|c|c|c|}
\hline & $\begin{array}{c}\mathbf{0 1} \text { - Living room } \\
\text { in a cold season }\end{array}$ & $\begin{array}{c}\mathbf{0 2} \text { - Living room } \\
\text { in a hot season }\end{array}$ & $\begin{array}{c}\mathbf{0 3} \text { - Bedroom } \\
\text { in a cold season }\end{array}$ & $\begin{array}{c}\text { 04 - Bedroom } \\
\text { in a hot season }\end{array}$ & 05 - Kitchen \\
\hline January & 21.38 & - & 21.57 & - & 21.22 \\
\hline February & 20.69 & - & 20.88 & - & 19.90 \\
\hline March & 20.93 & 20.15 & 21.04 & 19.34 & 20.56 \\
\hline April & - & 23.22 & - & 22.62 & 23.76 \\
\hline May & - & 23.61 & - & 22.85 & 24.14 \\
\hline June & - & 29.49 & - & 29.13 & 29.74 \\
\hline July & - & 29.75 & - & 29.27 & 29.98 \\
\hline August & - & 32.75 & - & 32.39 & 32.27 \\
\hline September & - & 32.79 & - & 32.21 & 32.66 \\
\hline October & - & 29.67 & - & 29.00 & 30.09 \\
\hline November & 27.56 & 24.88 & 29.10 & 24.60 & 26.60 \\
\hline December & 22.60 & - & 23.97 & - & 21.56 \\
\hline
\end{tabular}

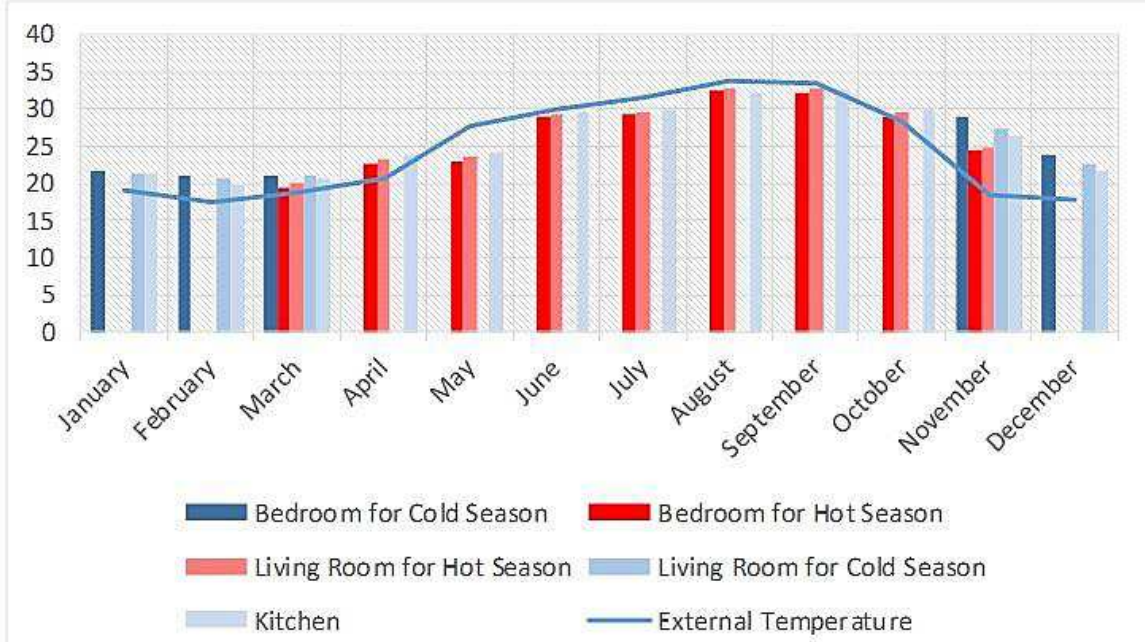

Fig. 9: Average temperature inside an old house [ArchiCad software].

According to the collected information, the inhabitants of the old house feel thermal comfort just in seven months of the year while using no air conditioner, Fig. 9. The highest temperature was reported to be about $32{ }^{\circ} \mathrm{C}$ in August and September and then about $29^{\circ} \mathrm{C}$ in October, June, and July, having little difference with the comfort range. The lowest temperature was $19{ }^{\circ} \mathrm{C}$ in February and March, having little difference with the comfort range. As it was mentioned in the theoretical foundations, residential places in old houses of Bushehr were separated in cold and hot seasons and placed at different levels. Each family used to move to other rooms with a better air condition at the beginning of the hot or cold seasons. Moving from winter rooms to summer rooms used to occur in the middle of March; however, the movement from summer rooms to winter rooms took place in the middle of November. These conditions were variable due to climate variations in each year; hence, both of the months are considered as hot and cold months in the table above.

\subsection{Analyzing new house}

Here is a four-year-old house located at Behbahani neighborhood beside the old house, which has a common type of new houses for analysis, Fig. 10. Generally new houses have more fans because they are built with a lower cost. In the new architecture backyards are usually in the back part of building without any specific purpose. The stairs and elevators are in a confined place and are being used for traffic only. In these new types of architecture semi-open spaces are rarely found and they are not in the proper places, so they do not play an important role in ventilation. New types of balconies do not cover the alleys, so the climate comfort is not prepared for passer-byes. In residential places, bedrooms, living rooms and services like bathrooms and kitchens are tightly packed together 
with no special arrangements to enhance airflow in the building. The ground floor has become parking for cars, without any special usage. Roofs and balconies are mostly decorative in appearance and are never used by residents. Wall materials are generally clay bricks and cement. Exterior walls have 20 $\mathrm{cm}$ thickness without any kind of heat insulation. Windows situations have not been considered to control wind flow. The glass surface area in the window is a lot, they are made from plain glass. There is not any kind of technology or special tools to reduce the radiation on windows.

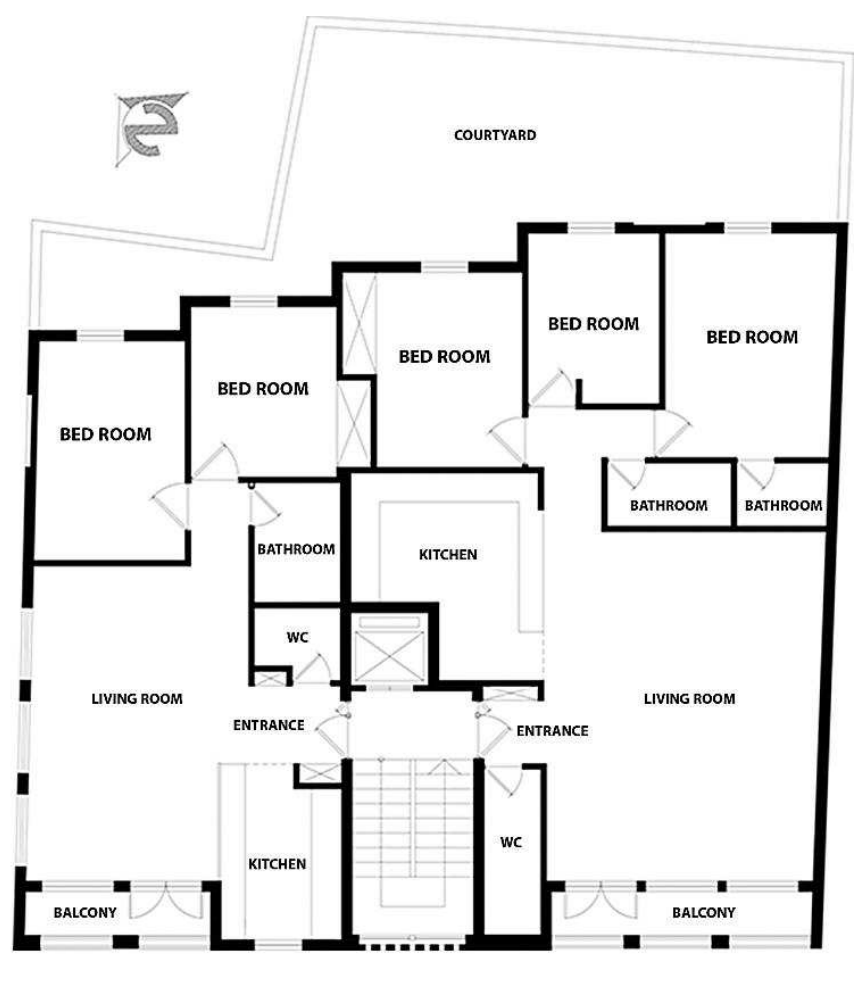

Fig. 10: New house plan.

Table 2: Average monthly temperature in the new house [ArchiCad software].

\begin{tabular}{|c|c|c|c|c|c|c|c|c|c|c|c|c|}
\hline & Jan & Feb & March & April & May & June & July & Aug & Sep & Oct & Nov & Dec \\
\hline 01 - Bedroom & 22.17 & 23.24 & 23.24 & 30.62 & 31.48 & 39.22 & 39.71 & 43.69 & 43.87 & 40.64 & 33.01 & 25.61 \\
\hline 02 - Living room & 22.20 & 23.20 & 24.18 & 30.07 & 32.15 & 39.31 & 40.37 & 43.70 & 43.26 & 38.49 & 29.56 & 23.65 \\
\hline 03 - Kitchen & 23.22 & 24.03 & 24.43 & 31.38 & 32.06 & 40.13 & 40.80 & 44.61 & 44.18 & 39.66 & 31.6 & 24.41 \\
\hline
\end{tabular}

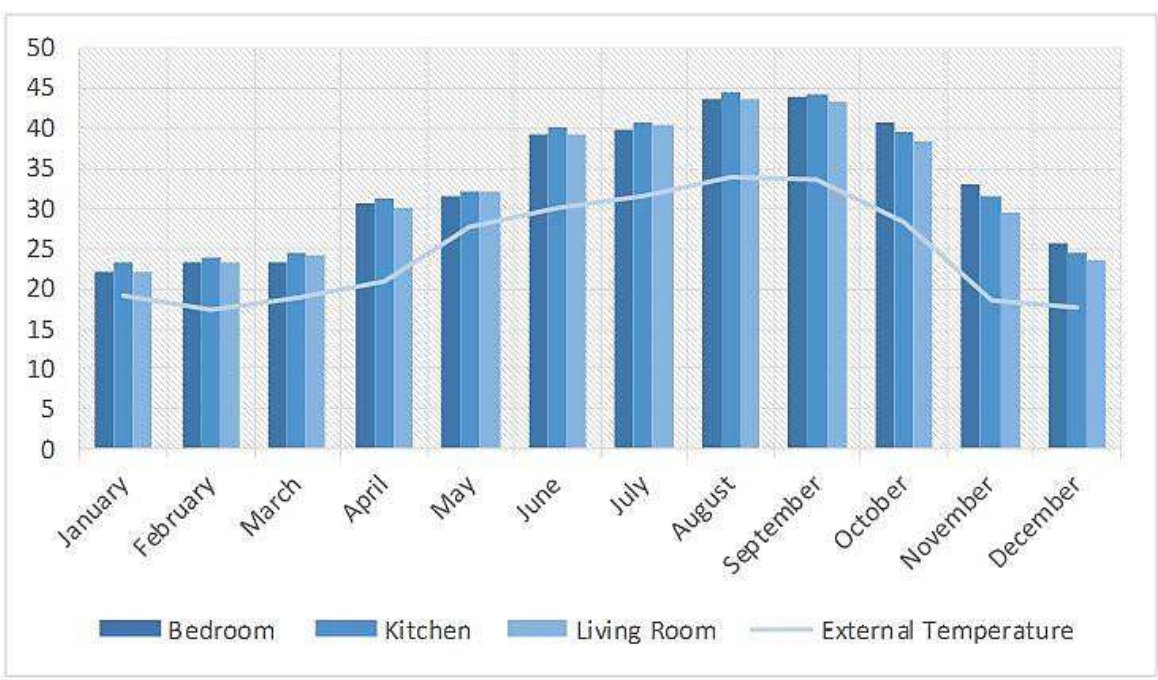

Fig. 11: Average temperature inside new house [ArchiCad software]. 
According to the collected information, the inhabitants of the new house feel thermal comfort just in four months of the year while using no air conditioner, Table 2 . The highest temperature $\left(44^{\circ} \mathrm{C}\right)$ is experienced in August and September, which is $15^{\circ} \mathrm{C}$ higher than the comfort range. Afterward, October, June, and July were the hottest months with temperatures $11^{\circ} \mathrm{C}$ higher than the comfort range. In April, May, and November, the temperature was about $32{ }^{\circ} \mathrm{C}, 3{ }^{\circ} \mathrm{C}$ higher than the comfort range. The lowest temperature was $22{ }^{\circ} \mathrm{C}$ in January. As shown in the diagram above, the average monthly temperature of places inside the new houses is always higher than the average temperature of outside with impressive rate; therefore, it makes the inhabitants feel much heat, which is annoying in the hot and humid climates, Fig. 11.

\section{Conclusion}

Bushehr's ancient texture is built in accordance with hot and humid climate. In such a context, there is a strong connection between different spaces and places to provide shadows, prevent radiation, and present more natural ventilation due to making the severe climate conditions better from the city and urban spaces to the tiny spaces and places like buildings and their special details like doors and windows. The new house's function is not according to the features of the historical texture so that these houses do not work properly. The new houses fail to provide thermal comfort for inhabitants and destroy the climate system and balance.

Fortunately, it is feasible to prepare instructions for designing new buildings by a study on the architecture and function of existing old buildings in the urban fabric in a way that not only the newlyconstructed buildings meet today's inhabitants's needs but also are in a harmony with the historical pattern of the city. The purpose of this harmonization is to create thermal comfort for inhabitants, reduce energy consumption in buildings, and follow the valuable historical texture in the design of new buildings.

- In the first step, preservation and revitalization of prevalent patterns in historical fabric and its goals should be considered in the design of newly-constructed buildings. Besides their social function, urban fabric, passageways and squares should improve climatic conditions. It is essential to create a height difference of buildings in specific locations in order to produce serrated fabric in the skyline of buildings for higher utilization of regional wind flow and directing it to lower levels. Sagacious placement of taller buildings among others creates turmoil in the wind flow particularly in the edge of squares and passageways. Moreover, it is possible to increase the air current by creating protuberances in the façade of buildings located adjacent to passageways and produce shadow for the comfort of pedestrians.

- In the second step, preservation and revitalization of existing spaces in the architecture of old buildings should be considered which are influential in the improvement of natural ventilation in buildings. Embedding central courtyards in the design of building blocks which work as artificial exhaust fans, placing semi-open spaces (such as Tarmeh and Shenashil) between living spaces in proper locations to improve the air circulation and create thermal comfort for residents, designing staircases not only as the connecting elements but also for enhancing vertical ventilation in buildings, are some examples. Besides, the harsh climatic conditions can be moderated by installing sunshades and growing plants on rooftops and balconies and turning them into spaces for relaxation and leisure time of dwellers specifically at nights when it is cooler in the rooftop.

- In the next step, preservation and revitalization of related details should be considered. Take, for example, double-shelled design of façade and use of wood in accordance with prevalent historic pattern in the fabric, placement of openings in appropriate locations and directions in order to lead the wind into the building, use of blinds in the design of openings for creating shadow on them, construction of light-colored exterior walls in double-shelled form with thermal insulation, use of local materials concerning the climate such as coral porous rocks existing in the area and materials with low thermal mass. All these items are effective in improving the climatic conditions and providing the thermal comfort for residents.

\section{Refrences}

[1] Iran Meteorological Organization [online 20.12.2019.], http://www.irimo.ir/.

[2] WATSON, D. - LABS, F. K.: Climate design: energy - efficient building principles and practices. Mc GraW-Hill publications, 1983. 
[3] RANJBAR, E.: Urban design master degree thesis: the review of climate sustainability standards due to designing public spaces of new cities around Persian Gulf (case study: Bushehr-alishahr). Tarbiat Modarres University, Faculty of art and architecture, 2007.

[4] Cultural Heritage of Bushehr Province's photo Archives.

[5] GHOBADIAN, V.: Climate analysis of the traditional Iranian buildings. Tehran university publications, 2006.

[6] PIRNIA, M. - MEMARIAN, G. H.: Iranian architecture. Soroushe danesh publications, 2008.

[7] POURJAFAR, M. - RANJBAR, E. - KHALIJI, K.: Innovations in Climatic Designing Due to the Wind Flowing Through the Old Bushehr. Journal of fine arts, Vol. 7, No. 13, 2010, pp. 17-34.

[8] DEKAY, M. - BROWN, G. Z.: Sun, wind \& light: architectural design strategies, 2001.

[9] MEMARIAN, G. H.: Introduction to the Iranian residential architecture. Soroushe danesh publications, 2007.

[10] PIRNIA, M. - MEMARIAN, G. H.: Islamic Architecture of Iran. Soroushe danesh publications, 2006.

[11] KASMAI, M.: Climate and architecture. 2nd edition, khak publications, 2006. 